\title{
FORMAS CONTEMPORÁNEAS DE ESCLAVITUD Y TRATA DE SERES HUMANOS: UNA PERSPECTIVA DE GÉNERO
}

\author{
Cristina Guisasola Lerma*
}

Resumen: La trata de seres humanos con fines de explotación constituye una grave vulneración de los derechos humanos y a la par supone una manifestación extrema de la situación de violencia y desigualdad en la que se encuentran las mujeres en muchos lugares del mundo: un $71 \%$ de las víctimas de trata y explotación son mujeres y niñas.

El trabajo comienza poniendo de manifiesto el compromiso y las acciones llevadas a cabo por los instrumentos internacionales y comunitarios $y$, tras analizar la regulación en el Derecho Penal español, concluye con la necesidad de reforzar el marco normativo con una ineludible perspectiva de género, que permita incrementar las herramientas legales para perseguir estos delitos, intensificando las acciones para la prevención, la protección de las víctimas, y la lucha contra esta lacra social desde una perspectiva global e interdisciplinar.

Recibido: enero 2019. Aceptado: mayo 2019

*Profesora Titular de Derecho Penal. ORCID ID: 0000-0001-7503-8466 Departamento de Derecho Público. Facultad de Ciencias Jurídicas y Económicas de la Universidad Jaume I. Avenida de Vicent Sos Baynat, s/n, 12071 Castellón de la Plana, Castellón. E-mail: cguisa@uji.es 
Palabras clave: delito de trata de seres humanos; moderna esclavitud; género; explotación laboral; explotación sexual.

\title{
CONTEMPORARY FORMS OF SLAVERY AND TRAFFICKING IN HUMAN BEINGS: A GENDER PERSPECTIVE
}

\begin{abstract}
Trafficking in human beings for the purpose of exploitation constitutes a serious violation of human rights and at the same time, it represents an extreme manifestation of the situation of violence and inequality in which women find themselves in many parts of the world: $71 \%$ of the victims of trafficking and exploitation are women and girls. The work begins by highlighting the commitment and actions carried out by international and community instruments and, after analyzing the regulation in Spanish Criminal Law, concludes with the need to reinforce the regulatory framework with an unmistakeable gender perspective, allowing an increase in the legal tools to prosecute these crimes. Such approach will intensifyi the actions for the prevention, the protection of the victims, and the fight against this social scourge from a global and interdisciplinary perspective.
\end{abstract}

Keywords: Traffick in human beings; modern slavery; gender; forced labour, forced marriage.

"Slavery is terrible for men; but it's more terrible for women. Superadded to the burden common to all, they have wrongs, and sufferings, and mortifications peculiarly their own"'"

Harriet Jacobs, 1861

\section{Nuevas formas de esclavitud en la sociedad contemporánea}

\section{Planteamiento general y precisiones conceptuales}

La esclavitud ${ }^{1}$ constituye la forma de servidumbre humana más absoluta y ha existido en todos los períodos históricos

1 De acuerdo con una de las acepciones del Diccionario de la Real Academia Española, esclavitud es la "sujeción excesiva por la cual se ve sometida una persona a otra, o a un trabajo u obligación".

Estudios Penales y Criminológicos,

vol. XXXIX (2019). ISSN $1137-7550:$ 589-642 -176- hitp://dx.doi.org/10.15304/epc.39.5760 
desde la Antigüedad ${ }^{2}$. No obstante, cuando se alude a ella nos viene a la mente en un primer momento los años de colonialismo en América, la esclavitud negra para subsanar la falta de mano de obra. En los Estados Unidos la esclavitud tuvo un componente claramente racista, y el fin de la misma no supuso el fin de la marginación y la violación de los derechos de los negros.

En el siglo XX la esclavitud tradicional prácticamente había dejado de existir, sin embargo, otras formas de sometimiento continúan en nuestros días: pese a la promulgación en 1926 de la Convención para la abolición de la esclavitud, y de la Declaración Universal de los Derechos Humanos de 1948 -que en su artículo 4 proclama que "la esclavitud y la trata de esclavos están prohibidas en todas sus formas"- todavía siguen existiendo diferentes formas de esclavitud, fundamentalmente a partir de la explosión demográfica tras la Segunda Guerra Mundial, unida al empobrecimiento de un importante porcentaje de la población global, motivada entre otras razones por los conflictos armados y la brecha entre países pobres y ricos ${ }^{3}$. En la actualidad la esclavitud moderna se da de manera encubierta y ocurre por situaciones de explotación altamente abusivas que las personas no pueden rechazar por estar en situación de necesidad o bajo amenazas, como veremos detenidamente. A diferencia de las formas de esclavitud tradicionales, los tratantes ya no reclaman la propiedad sobre los mismos, pero se adquiere el control sobre los mismos y se utiliza la violencia o la amenaza para mantener$\operatorname{los}^{4}$, desechándolos cuando dejan de serles útiles. El concepto jurídico-internacional de esclavitud recogido en la Convención

2 Aristóteles justificaba la existencia de hombres esclavos con base en cuatro tipos de razones: históricas, coyunturales, metodológicas y filosóficas. Puede verse al respecto en GARCÍA MERCADO, M.A.: "El problema de la esclavitud en Aristóteles", en Pensamiento 2008, p. 152 y ss.

3 Analiza con detenimiento estas causas VILLACAMPA ESTIARTE, C.: "La moderna esclavitud y su relevancia jurídico-penal” en Revista de Derecho Penal y Criminología, julio 2013, p. 318.

4 BALES, K.: La nueva esclavitud en la era global, 2000, p. 6. 
de $1926^{5}$ se mantiene inmodificado en la Convención suplementaria sobre la Abolición de la Esclavitud, la Trata de Esclavos y las Instituciones y Prácticas Análogas a la Esclavitud de 7 de septiembre de 1956 de Naciones Unidas, sin embargo el mismo se considera ayuno de actualización, puesto que contempla una definición más apegada más al concepto tradicional de esclavitud $^{6}$. La esclavitud del siglo XXI se caracteriza por una explotación económica de la persona esclavizada, ya sea sexual o laboralmente, abusando de una situación de vulnerabilidad y que con frecuencia puede estar oculta a simple vista ${ }^{7}$. La misma adopta diversas formas si bien BALES ${ }^{8}$ las concreta en tres en la actualidad: la prendaria, la más parecida a la antigua esclavitud, que suele darse en África y en los Países Árabes; la servidumbre por endeudamiento, la forma más extendida en todo el mundo; y la esclavitud contractual, donde se utilizan las formas laborales para ocultar la esclavitud.

En este contexto resulta frecuente confundir el delito de trata de seres humanos con el fenómeno delictual de la esclavitud, sin embargo, como analizaremos, la trata es el mecanismo para conseguir explotar a las personas, teniendo, por tanto, un carácter instrumental ${ }^{9}$, tal y como recoge la jurisprudencia ${ }^{10}$

5 Según su art. 1.1. se entiende por esclavitud: "el estado o condición de un individuo sobre el cual se ejercitan los atributos del derecho de propiedad o algunos de ellos".

6 De inservible lo califica MAQUEDA ABREU en: "Demasiados artificios en el discurso jurídico sobre la trata de seres humanos" en Liber Amicorum. Estudios Jurídicos en Homenaje al Prof. Terradillos, Valencia, 2018, p.1207.

7 Ese fue el motivo que llevó a la fotógrafa humanitaria estadounidense, Lisa Kristine, a comenzar a trabajar como voluntaria con la ONG Free the slaves, a documentar a lo largo de los últimos 30 años y a sacar a la luz imágenes la esclavitud moderna y el trabajo infantil.

8 BALES, K.: La nueva esclavitud en la economía global, Madrid, 2000

9 MAQUEDA ABREU, M.: ob.y loc.cit; la misma autora en: "Trata y esclavitud no son lo mismo, pero ¿qué son?” en Estudios Jurídico Penales y Criminológicos. En homenaje al Prof.Dr.H.C.Mult.Lorenzo Morillas Cueva, Madrid, 2018, p. 1251 y ss; VILLACAMPA ESTIARTE, C.: "El delito de trata de seres humanos en Derecho Penal español tras la reforma de 2015" en El derecho ante las formas contemporáneas de esclavitud, 2017, p. 465;

Estudios Penales y Criminológicos,

vol. XXXIX (2019). ISSN $1137-7550:$ 589-642 -178- hitp://dx.doi.org/10.15304/epc.39.5760 
Adicionalmente, es una realidad que ambos fenómenos afectan mayoritariamente a mujeres y niñas en el caso de la explotación sexual (95\% de las víctimas) -tal y como se apunta en el Plan integral de lucha contra la trata de mujeres y niñas con fines de explotación sexual (2015-2018) del Ministerio de Sanidad, Servicios Sociales e Igualdad- pero también en otros ámbitos de explotación como el laboral, en sectores altamente feminizados como el empleo del hogar o los matrimonios forzados. De ahí que se esté reconociendo internacionalmente que la trata de mujeres es una forma de violencia de género, donde la violencia sobre ellas recae precisamente porque son mujeres, esto es, repercute en ellas por su género, un género que, como bien apunta SERRA ${ }^{11}$, constituye su esencia como personas.

El primer texto normativo en el ámbito internacional que acoge un concepto de trata fue el Protocolo para prevenir, reprimir y sancionar la trata de personas, especialmente de mujeres y niños, que complementa la Convención de Naciones Unidas contra la Delincuencia Transnacional, celebrado en el año 2000 y ratificado por España en 2002 (en adelante, Protocolo de Palermo). De acuerdo con la definición recogida en su art. 3 la trata consiste en: "La captación, el transporte, el traslado, la acogida o recepción de personas recurriendo a la amenaza o al uso de la fuerza u cualquier otras formas de coacción, al rapto, fraude, engaño, abuso de poder o de una situación de vulnerabilidad o el ofrecimiento o la concesión de pagos o beneficios para obtener el consentimiento de una persona que tenga autoridad sobre otra con fines de explotación". En dicho instrumento, pese a no incluir de manera expresa la perspectiva de género, se pue-

POMARES CINTA, E.: El Derecho penal ante la explotación laboral y otras formas de violencia en el trabajo, Valencia 2013, p. 139.

10 Así, por ejemplo, las SSTS de 4 de febrero de 2014 (TOL 4110012) y de 5 de abril de 2016 (TOL 5691251).

11 SERRA CRISTOBAL, R.: "La trata de personas como una de las formas más atroces de violencia contra la mujer”, en EMARTÍN SÁNCHEZ (DIR): Estudio integral de la violencia de género: un análisis teórico-práctico desde el derecho y las ciencias sociales, Valencia, 2018, p. 271. 
de deducir la misma de su Preámbulo declarando que: “...para prevenir y combatir eficazmente la trata de personas, especialmente mujeres y niños...” y “...para combatir la explotación de las personas, especialmente mujeres y niños...".

En el contexto europeo, la trata también aparece definida de forma similar en el Convenio del Consejo de Consejo de Europa sobre la lucha contra la trata de seres humanos (Varsovia, 16 de mayo de 2005) ${ }^{12}$. Entre los propósitos de explotación del delito de trata se recoge, junto a la imposición de trabajo o servicios forzados, "la esclavitud o prácticas similares a la esclavitud", esto es, la trata constituye el delito antecedente respecto de los tipos penales que sancionan situaciones de explotación. Como novedad se adopta la perspectiva de género, contemplando entre sus objetivos:

“1.a) Prevenir y combatir la trata de seres humanos, garantizando la igualdad de género;

1.b) Proteger los derechos humanos de las víctimas de la trata, diseñar un marco global de protección y de asistencia a las víctimas y a los testigos, garantizando la igualdad de género, $y$ asegurar investigaciones y actuaciones penales eficaces"

También en el ámbito europeo, la trata y la explotación sexual se recogen como forma de violencia contra la mujer en el Convenio europeo sobre prevención y lucha contra la violencia hacia las mujeres y la violencia doméstica, firmado en Estambul en 2011, ratificado por España en 2014. Por su parte la Unión Europea aborda la violencia contra las mujeres y la trata de seres humanos, en la Directiva 2011/36/UE relativa a la prevención y lucha contra la trata ${ }^{13}$ y a la protección de las

12 Ratificado por España el 29 de febrero de 2009 (Instrumento de Ratificación, BOE-A-2009-14405). El Convenio tiene por objeto prevenir la trata de seres humanos, proteger a las víctimas y encausar a los traficantes. Abarca todas las formas de trata (ya sea nacional o transnacional, vinculada con el crimen organizado o no) y contempla a todas las víctimas de la trata (mujeres, hombres y niños), así como todas las formas de explotación.

13 Publicado en el de Diario Oficial de la Unión Europea el 15 de abril de 2011. Disponible en https://www.boe.es/doue/2011/101/L00001-00011.pdf 
víctimas, por la que se sustituye la Decisión marco 2002/629/ JAI del Consejo, e introduce disposiciones comunes teniendo en cuenta la perspectiva de género para mejorar la prevención y la protección de las víctimas. A este respecto se pone de manifiesto como, aunque la trata afecta a ambos géneros, las mujeres se ven más afectadas de manera diferente puesto que, por ejemplo, tienen más probabilidades de terminar como empleadas domésticas o en la industria del sexo, esto es, tienden a ser más vulnerables a la trata debido a su situación económica y social y su posición de desventaja en el mercado laboral ${ }^{14}$. En particular, por lo que se refiere a la prostitución forzada y la explotación sexual, resulta conveniente aludir a la Resolución del Parlamento Europeo, de 26 de febrero de 2014, sobre explotación sexual y prostitución y su impacto en la igualdad de género (2013/2103(INI)) P7_TA (2014)0162. Dicha Resolución reconoce que constituyen violaciones de la dignidad humana, intrínsecamente ligadas a la desigualdad de género en la sociedad, y una forma de violencia contra las mujeres en general. A su vez destaca los vínculos entre la prostitución y la trata de personas, en particular la primera alimenta el tráfico de mujeres y mujeres menores de edad vulnerables. Recomienda asimismo afrontar y valorar el estado de la cuestión sobre trata de mujeres y perspectiva de género bajo las tendencias que se inspiran hoy en el sistema nórdico, en especial el sueco, que aplica dicha perspectiva en todas sus leyes y para luchar contra las redes de trata y proxenetismo penaliza al cliente de la prostitución para frenar dichas mafias ${ }^{15}$.

14 Prevenir, Combatir, Proteger. La Trata de Seres Humanos. Comentario conjunto de las Naciones Unidas a la Directiva de la Unión Europea. Un enfoque basado en los derechos humanos. 2011; disponible en https://www. acnur.org/fileadmin/Documentos/BDL/2013/9250.pdf

15 En declaraciones de la ministra de Igualdad de Suecia, en un seminario dedicado a la trata y la prostitución organizado por la Embajada sueca en Madrid, Asa Regner parte de la premisa de que si no hay demanda no habrá oferta y que se basa en la idea de que la prostitución forzada está anclada en la desigualdad de género y es una forma de violencia contra la mujer, vid. "Cuando pagar por sexo es delito. El modelo sueco, que penaliza al cliente de la prostitución para frenar las mafias se extiende a cinco países de la Unión Europea", El País, 17 abril 2017. 
En este contexto, en la Estrategia de la Unión Europea para la erradicación de la trata de seres humanos 2012-2016 se señala que la violencia contra las mujeres es una de las causas profundas de la trata de seres humanos. Pues bien resulta imprescindible detenernos en la Resolución del Parlamento Europeo, de 12 de mayo de 2016, sobre la aplicación de la Directiva 2011/36/UE. Dicha resolución parte de la consideración de que el género no causa por sí vulnerabilidad, siendo muchos los factores que contribuyen a crear dicha situación de vulnerabilidad para las mujeres y menores: pobreza, sexismo, discriminación y desigualdades económicas, sociales, educativas y de formación entre hombres y mujeres. En consecuencia se subraya que en el marco legal y político de la Unión se reconoce que la trata es un fenómeno específico de género y pide a los Estados miembros que se adopten medidas específicas de género dirigidas a la prevención, asistencia y apoyo a sus víctimas, destacando como la violencia contra las mujeres y las desigualdades de género son una de las causas primordiales de la trata. En particular, insta a los Estados a que garanticen una prestación de servicios a las víctimas de trata, diferenciada en función del género, adaptándola a sus necesidades y a las específicas derivadas de la forma de trata a la que hayan sido sometidas. En esta dirección, la posterior Resolución del Parlamento Europeo de 5 de julio de 2016 reitera la consideración de la trata de seres humanos como un delito con un claro componente de género.

Ahora bien, la Evaluación Europea ${ }^{16}$ de la Aplicación de la Directiva 2011 identifica una falta de implementación de medidas basadas en la perspectiva de género en el tratamiento que se da a la trata de personas. Al analizar la situación en España se apunta que, pese a los esfuerzos realizados por nuestro país -el legislador español tipifica en 2010 el delito de trata- el foco está centrado en las víctimas de explotación sexual, lo que invisibiliza a las víctimas de otras formas de explotación ${ }^{17}$; a

16 Publicada por la Unidad de Evaluación de Impacto de la Dirección General del Servicio de Parlamentario de Investigación.

17 Cfr. FARALDO CABANAS, P. "Donde están las víctimas de trata? Obstáculos a la identificación de las mujeres víctimas de trata en España", en 
ello se suma la identificación primaria de las víctimas de trata como migrantes ilegales y solo secundariamente como víctimas de un delito. Adicionalmente resulta criticable que la legislación española no haya tenido en cuenta el concepto de "violencia de género" empleado por los organismos internacionales. El concepto de violencia de género empleado en la Ley Orgánica $1 / 2004$ de medidas de protección integral de violencia de género es restrictivo, únicamente hace referencia a mujeres que hayan tenido o tengan un vínculo afectivo con su agresor ${ }^{18} \mathrm{y}$ solo comprende como violencia de género "todo acto de violencia física y psicológica, incluidas las agresiones a la libertad sexual, las amenazas, las coacciones o la privación arbitraria de libertad". Consideramos pues que debe procederse a ampliar el concepto de violencia de género de la LO 1/2004, que trascienda a la llevada a cabo en el seno de la pareja o ex pareja ${ }^{19}$. En esta dirección, la Sala II del Tribunal Supremo ha considerado en la reciente sentencia de 19 de noviembre de 2018 que la agravante de género -añadida al CP por la reforma de 2015- debe aplicarse en todos los casos en que se actúe contra la mujer por el hecho de serlo, aunque entre el autor del delito y la víctima no exista ningún tipo de relación ${ }^{20}$.La Sala confirma que dicha

Libro de Actas Conferencia Internacional "Día europeo contra el tráfico de seres humanos", octubre 2017.

18 De acuerdo con el art. 1.1 de la Ley Orgánica 1/2004, de 28 de diciembre de Medidas de Protección Integral contra la Violencia de Género, violencia de género es "la violencia que, como manifestación de la discriminación, la situación de desigualdad y las relaciones de poder de los hombres sobre las mujeres, se ejerce sobre éstas por parte de quienes sean o hayan sido sus cónyuges o de quienes estén o hayan estado ligados a ellas por relaciones similares de afectividad, aun sin convivencia".

19 En este sentido, VILLACAMPA ESTIARTE, C. "Pacto de estado en materia de violencia de género: ¿más de lo mismo? Revista Electrónica de Ciencia Penal y Cri- minología. 2018, núm. 20-04, pp. 15 y ss. Disponible en internet: http://criminet.ugr.es/recpc/20/recpc20-04.pdf; ORBEGOZO, I.: "La Víctima de Trata Sexual y su Des-protección en la Ley Integral contra la Violencia de Género 1/2004 (The Sexual Trafficking Victims and Des-protection in the Law Against Gender Violence 1/2004) en Oñati Socio-legal Series, v. 5, n. 2, 2015, p. 637.

20 TOL 6919645 
agravante es compatible con la de parentesco, puesto que si bien esta última se aplica siempre que medie entre autor y víctima las relaciones de afectividad o convivencia que recoge, la agravante de género tiene un fundamento subjetivo "necesitando que concurra en el autor del delito un ánimo de mostrar su superioridad frente a la víctima mujer y demostrarle que ésta es inferior por el mero hecho de serlo".

\section{Aproximación a la magnitud del fenómeno}

Conforme a lo expuesto, el delito de trata, de seres humanos supone la captación -y otras acciones similares- de millones de mujeres, niños y hombres con numerosos propósitos, incluidos el trabajo forzoso y el sexo. Cometido en gran medida en el marco de la delincuencia organizada ${ }^{21} \mathrm{y}$ con invisibilidad de las víctimas resulta difícil de cuantificar ${ }^{22}$, si bien podemos darnos cuenta de su magnitud y del creciente alcance del fenómeno, si atendemos a los recientes Informes y estudios en la materia, publicados a nivel internacional ${ }^{23}$. A este respecto, de acuerdo con el segundo Informe de la Comisión (2018) al Parlamento Europeo y al Consejo, sobre los progresos realizados en la lucha contra la trata, se destaca como la Comisión ha trabajado con los Estados miembros, con Eurostat y con las autoridades

$21 \mathrm{Al}$ cierre de este artículo se publicaba la noticia de la detención en Málaga de una violenta organización de gánsteres polacos dedicados a la trata, captando mujeres con problemas económicos, ofreciéndoles dinero y convirtiéndolas posteriormente en sus esclavas, obligándolas a saldar sus deudas prestando servicios sexuales. Vid. "Los hombres que marcaban a las mujeres" en El País, 28 abril 2019.

22 Acerca de la debilidades metodológicas empleadas en la cuantificación de los datos, VILLACAMPA ESTIARTE: "La moderna esclavitud..." cit., p.319 y ss.

23 El 15 de abril de 2013 fue presentado el primer informe sobre trata de seres humanos de Eurostat (oficina estadística de la Unión Europea). La publicación recoge por primera vez las estadísticas sobre este fenómeno en el ámbito de la Unión Europea, e incluye los datos relativos a los años 2008, 2009 y 2010. http://ec.europa.eu/anti-trafficking/EU+Policy/Report_DGHome_Eurostat;jsessionid=6thhST5JfyDb02y8vpLyDd7FLyfWqxjWhyLP kwxvb5whFDh16tHh!40560286

Estudios Penales y Criminológicos,

vol. XXXIX (2019). ISSN 1137-7550: 589-642 -184- hitp://dx.doi.org/10.15304/epc.39.5760 
estadísticas para mejorar los datos disponibles, si bien continúan apreciándose deficiencias en dicha provisión, subrayando la importancia del acceso a datos fiables como requisito para un adecuado seguimiento y una mejor formulación de políticas.

Ahora bien, es una realidad, como ya se ha expuesto, que la trata de personas afecta de manera desproporcionada a mujeres y niñas, por lo que podemos afirmar que no es neutral en cuanto al género, como bien señala LLORIA ${ }^{24}$. La trata de mujeres y la prostitución es un negocio multimillonario, según los datos de un informe conjunto realizado por Europol e Interpol, el segundo mayor delito trasnacional, solo por detrás del narcotráfico. Se observa asimismo un acusado incremento del número de mujeres y niñas víctimas de trata en la ruta del Mediterráneo central con fin de explotación sexual en la UE. Los expertos afirman que se podrían mover 25.000 millones de euros al año en todo el mundo. En Europa supone unos 2.280 millones de euros anuales, siendo especialmente destacable la trata con fines de explotación sexual y la de carácter laboral tiene lugar, sobre todo, en el servicio doméstico, sectores de la agricultura, construcción y restauración ${ }^{25}$. En nuestro país se calcula que supone un movimiento de 5 millones de euros al día ${ }^{26}$, no afectando solo a las grandes ciudades, sino también a núcleos urbanos de tamaño medio ${ }^{27}$.

24 LLORIA GARCÍA, P.: "Una ley integral contra la trata, con perspectiva de género" en Agenda Pública, El País, 26 marzo 2019.

25 G.Susaj/K.Nikopoulou/A.Giménez-Salinas Framis, Coord.), La Trata de Personas con Fines de Explotación Laboral. Un estudio de aproximación a la realidad en España, Accem 2006, p. 40; Combating trafficking as modernday slavery: a matter of rights, freedom and security, Informe Anual de la Organización para la Seguridad y la Cooperación en Europa, 9 de diciembre de 2010; BALES, TRODD, KENT: Modern Slavery. The secret world of 27 million People, 2009.

26 Datos facilitados a la prensa en el Día mundial contra la trata, Diario Mediterráneo 31 julio 2018.

27 Desde la tipificación del delito de trata en la reforma del CP de 2010, según datos de la Fiscalía provincial de Castellón, sección de Extranjería, se han producido hasta 51 detenciones, entre Guardia Civil y Policía Nacional y 36 liberaciones de víctimas. 
Pues bien, si acudimos al Informe de Naciones Unidas sobre trata de personas publicado en 2016 (Oficina contra la Droga y el Delito) ${ }^{28}$ establece que las mujeres y niñas comprenden el 71 por ciento de las víctimas. La trata de personas con fines de explotación sexual y trabajos forzados continúan siendo las modalidades más detectadas de este delito si bien existen también víctimas de trata de personas con fines de explotación de la mendicidad, matrimonios forzados o fraudulentos. El informe incluye un capítulo temático que se enfoca en las conexiones entre la trata de personas, la migración y los conflictos: las personas que huyen de la guerra y la persecución son particularmente vulnerables a la trata de personas. El Informe destaca que mujeres y niñas tienden a ser víctimas de trata de personas con fines de matrimonios forzados o explotación sexual.

Por su parte, el Informe de la Organización Internacional del Trabajo (OIT) sobre Estimaciones globales sobre la esclavitud moderna ${ }^{29}$, emitido en 2017 refleja que en los últimos años 89 millones de personas fueron sometidas a alguna forma de esclavitud moderna. $\mathrm{Si}$ atendemos al género, confirma que un $71 \%$ de las víctimas son mujeres y niñas, datos coincidentes con los de Naciones Unidas. Por lo que se refiere al año 2016 estas estimaciones mundiales examinaron diferentes formas de trabajo forzoso impuesto en la economía privada (16 millones de personas, siendo más las mujeres afectadas, un 57,6 5) e impuesto por el Estado (4,1 millones). El trabajo forzoso afecta en forma desproporcionada a las mujeres y niñas, que representan el 99 por ciento de las víctimas en la industria sexual comercial y el 58 por ciento en otros sectores ${ }^{30}$.

28 UNODC, Global Report on Traffiking in persons, 2016. El Informe completo está disponible en pdf en la siguiente dirección: https://www.unodc. org/documents/colombia/2016/Diciembre/2016_Global_Report_on_Trafficking_in_Persons.pdf

29 OIT: Global estimates of Modern Slavery, 2017; disponible en pdf en: ww.ilo.org/ipec/Informationresources/WCMS_596485/lang--es/index.htm

30 Vid. BALES, TRODD, KENT: "Their own sufferings: modern slavery for women and girls" en Modern Slavery. The secreto world of 27 million People, 2009, cit.,p. 65 y ss

Estudios Penales Y CRIMINOLÓGICOS,

vol. XXXIX (2019). ISSN $1137-7550:$ 589-642 -186- hitp://dx.doi.org/10.15304/epc.39.5760 
Un completo informe sobre la situación de la trata en el mundo, que contiene una fotografía de los esfuerzos y las acciones que cada país pone en marcha para luchar contra la trata de seres humanos es el "Informe sobre trata de personas" (trafficking in persons report) publicado anualmente por el Departamento de Estado de Estados Unidos. En relación a España, el Informe de 2018 reconoce el compromiso del país en la lucha contra esta lacra, así como proporciona una serie de recomendaciones para avanzar en la investigación y persecución del delito, así como en la protección y asistencia de las víctimas. En concreto, entre otras cosas, dada la extrema gravedad de este delito, se recomienda al gobierno de España incrementar las investigaciones, las acusaciones y condenas por este delito, en particular para los casos de trata con fines de explotación laboral.

Por su parte, el II Informe de Evaluación del Grupo de Expertos del Consejo de Europa sobre la lucha contra la trata de seres humanos (GRETA) publicado en junio de 2018 -Grupo que se encarga de evaluar la aplicación del Convenio por los países que lo han ratificado- subraya como en España la gran mayoría de las personas identificadas como víctimas eran mujeres y niñas (84\%) tratadas con fines de explotación sexual; sin embargo señala que estas cifras no reflejan la escala real de la trata de personas en nuestro país y que es probable que la explotación laboral esté infra visibilizada por la ausencia de denuncias y la dificultad de obtener testimonios de las víctimas de trata por la difícil situación en la que se encuentran.

A nivel interno, según los datos obtenidos de la Memoria de Fiscalía General del Estado de 2018, Unidad de Extranjería, durante el año 2017 el número de causas que tuvieron por objeto la investigación de cualquier modalidad de trata tipificada en el artículo 177 bis CP alcanzó la cifra de 122 diligencias, 37 más que en 2016 lo que representa el considerable aumento del $30,32 \%$. De ellas 103 eran trata con fines de explotación sexual, 8 trata laboral, 2 trata para la mendicidad, 1 de naturaleza mixta 
(laboral y mendicidad), 2 trata para la realización de actividades delictivas, 5 para matrimonios forzosos y 1 para la extracción de órganos. De acuerdo con los datos del Informe pormenorizado desarrollado en el documento «Diligencias de Seguimiento del Delito de Trata de Seres humanos» que se publica como anexo de la Memoria, la gran complejidad de este tipo de investigaciones - por su vinculación con el crimen organizado y la vulnerabilidad de las víctimas- explica, no solo que muchas de ellas no puedan ser concluidas tras años de múltiples diligencias sino también que pese a la existencia de indicios más que suficientes de la comisión del delito, sean archivadas de manera provisional.

Con la finalidad de aportar una herramienta útil para afrontar el tratamiento policial y judicial, el Consejo General del Poder Judicial ha sistematizado en un documento que fue presentado el pasado mes de noviembre de 2018 criterios de actuación que se consideran óptimos para alcanzar los resultados perseguidos: la "Guía de criterios de actuación judicial frente a la trata de seres humanos" ha sido dotada de un enfoque integral basado en los derechos humanos pero además teniendo en cuenta la perspectiva de género, en el sentido del distinto impacto que tienen las acciones y medidas contra la trata en hombres y mujeres. En relación a ellas se proponen y estudian tanto en fase de instrucción como en fase de juicio oral, con vocación de ser útil en el día a día de la Administración de Justicia.

\section{Alcance del delito de trata de seres humanos (art. 177 bis) desde un enfoque de género}

\section{Ubicación y bien jurídico protegido}

Pretendiendo cumplir con los mandatos de los compromisos internacionales, la reforma penal operada por LO 5/2010 de 20 de junio dotó de autonomía al delito de trata de seres humanos frente al delito de inmigración ilegal, con los que antes convivían. De manera que en el art. 318 bis se engloban las con- 
ductas relativas a la inmigración o tráfico ilegal de extranjeros, tipificando de modo separado, en un nuevo Título, la trata de seres humanos (art. 177 bis).

El legislador penal de 2015 consideró que -dado que este delito se introdujo en nuestro CP con anterioridad a la citada Directiva 2011- existían algunas cuestiones que no fueron reflejadas en la redacción inicial y que era preciso incluir para una completa transposición de la normativa europea, sin embargo no incrimina de manera expresa la esclavitud ni los trabajos forzados u obligatorios, debiendo reconducirse su castigo en función del tipo de explotación sufrida, cuestión que abordaremos al referirnos a los aspectos concursales.

Atendiendo a los diversos instrumentos internacionales, la trata se considera, una afrenta clara a los derechos y en particular a la dignidad de las personas. El bien jurídico tutelado es "la protección de la dignidad y la libertad de los sujetos pasivos que la sufren" "31, una de las diferencias con el mencionado delito de contrabando de inmigrantes ${ }^{32}$, en el que se tutela el interés estatal de controlar los flujos migratorios, de ahí el acierto de la nueva ubicación sistemática. Y hay acuerdo tanto en la jurisprudencia como en la doctrina en considerar como conceptos estrechamente vinculados a la interpretación del tipo penal el traslado, "el desarraigo, la indefensión, la cosificación y la comercialización de las víctimas" (SAP de Valencia de 21 junio de $2018)^{33}$. En atención a ello, el delito de trata también supone la puesta en peligro de aquellos otros bienes jurídicos protegidos en los delitos a través de los cuales se concrete la finalidad explotadora: delitos contra los derechos de los trabajadores, libertad sexual, integridad moral, etc.. ${ }^{34}$.

31 Exposición Motivos de la LO 5/2010.

32 Diferencias entre ambos que recoge nuestra jurisprudencia reciente (a título de ejemplo, la STS 29/03/2017), así como el CGPJ en la Guía de criterios de actuación judicial frente a la trata de seres humanos, cit., pag. 70.

33 TOL 6.677.227

34 En este sentido, POMARES CINTAS, E.: El Derecho penal ante la explotación laboral y otras formas de violencia en el trabajo, Valencia 2013, p. 123. 


\section{Conductas incriminadas, medios comisivos y finali- dades del delito de trata}

\subsection{Las modalidades de conducta alternativas.}

Las distintas modalidades expresan un desplazamiento de la víctima de la trata:

La captación es considerada como la conducta inicial que "comienza con la atracción de una persona para controlar su voluntad con fines de explotación, lo que equivale al reclutamiento de la víctima" (STS de 29 de marzo de 2017) ${ }^{35}$. A mayor vulneración social, mayor facilidad de captación, por ello las mujeres son más proclives a ser captadas como víctimas de trata, siendo el engaño uno de los elementos claves.

El transporte o traslado no requiere un desplazamiento transfronterizo de la víctima: las acciones pueden realizarse en territorio español, y en el caso de que adquiera naturaleza transnacional, debe cometerse "desde España, en tránsito o con destino a ella". Se excluye, por tanto, la persecución de la trata en el extranjero que no guarde un punto de conexión con España ${ }^{36}$. Esto viene siendo criticado desde la doctrina, alegando que en la normativa internacional no se contiene requerimiento territorial alguno y que, con ello, se sigue confundiendo trata e inmigración ilegal de manera que España corre el riesgo de quedarse corta en la criminalización de conductas de trata ${ }^{37}$.

El acogimiento o recepción de la víctima, tras una captación previa, con cualquiera de las finalidades de explotación ha de ser distinto al que puede tener con posterioridad de lograrse la explotación (STS 9 abril 2015) ${ }^{38}$. Y por último se incluye, tras la reforma de 2015, el intercambio o transferencia de con-

\footnotetext{
35 TOL 6.26 .830

36 POMARES: "El delito de trata de seres humanos con finalidad de explotación laboral" en RECPC, 2011, p.7.

37 VILLACAMPA ESTIARTE, C.: "El delito de trata de seres humanos en Derecho Penal español tras la reforma de 2015", ob. cit., p. 461.

38 TOL 4.839 .142
}

Estudios Penales Y CRIMINOĹGICOS

vol. XXXIX (2019). ISSN $1137-7550:$ 589-642 -190- hitp://dx.doi.org/10.15304/epc.39.5760 
trol sobre una persona, modalidad que evidencia el proceso de comercialización que sufre la víctima.

Recordemos que la fase de explotación no forma parte de las conductas típicas y, por tanto, no se requiere para la consumación del delito de trata (STS 24 de marzo 2017) ${ }^{39}$. Por su parte, si bien los actos preparatorios de la trata son punibles, la realidad criminológica muestra que el delito suele descubrirse cuando se ha ejecutado ya la explotación o en las fases previas a ella, de modo que también resulta problemático el castigo de la tentativa de la trata.

\subsection{Los medios comisivos. Tratamiento jurisprudencial.}

Las acciones descritas se han de llevar a cabo empleando alguno de los siguientes medios comisivos: "violencia, intimidación, engaño o abusando de una situación de superioridad, necesidad o vulnerabilidad de la víctima", medios que coinciden con los previstos en el delito del art.187.1 que tipifica la determinación a una persona mayor de edad a ejercer o mantenerse en la prostitución. Junto a los expuestos, con las modificaciones introducidas en 2015 se incluye un nuevo medio comisivo "la entrega o recepción de pago o beneficios para lograr el consentimiento de la persona que poseyera el control sobre la víctima".

Los medios relacionados son alternativos si bien, durante todo el proceso de la trata, suelen emplearse medios distintos:

Por lo que se refiere a la violencia, suele equipararse a la fuerza física sobre la víctima no requiriéndose la causación de lesiones físicas que conformarían, de producirse, el correspondiente delito de lesiones. Violencia que, como ya se ha dicho, afecta mayoritariamente a mujeres y niñas, de ahí que se haya reconocido internacionalmente que la trata de mujeres es una forma de violencia de género ${ }^{40}$, expresión de las relaciones de

39 TOL 6.026 .687

40 Declaración sobre la eliminación de la violencia contra la mujer, Asamblea General de Naciones Unidas; Convenio del Consejo de Europa sobre prevención y lucha contra la violencia contra las mujeres y la violencia doméstica. 
poder históricamente desiguales entre varones y mujeres, caracterizadas por la consecuente subordinación y opresión de estas últimas. La trata de personas involucra de algún modo todos los tipos de violencia de género, provocando graves dificultades para el desarrollo de las mujeres y niñas. Se incluyen aquí pues los supuestos de "trata forzada". El concepto violencia, sin matizaciones, es amplio y puede comprender no solo la física sino también la violencia psíquica, tal y como distingue el delito de violencia habitual del art. 173 CP, así como la Ley Orgánica 1/2004, si bien como ya advertimos, referida solo al ámbito doméstico.

El término intimidación ${ }^{41}$ viene identificándose en la jurisprudencia con las amenazas dirigidas a la víctima o terceros, con la finalidad de doblegar la voluntad, pero también alude al de coacciones ${ }^{42}$. En este sentido, se afirma que consiste en "la amenaza de, un mal que no es imprescindible que sea inmediato, bastando que sea grave, futuro y verosímil" (STS 28 mayo $2015)^{43}$. Basta que la intimidación sea suficiente para que en el caso concreto la víctima se haya visto compelida a claudicar ante las exigencias del sujeto activo ${ }^{44}$. En el delito de trata, atender a las circunstancias personales de la víctima requiere adoptar, según los casos una perspectiva de género ${ }^{45}$ o una perspectiva de minoría de edad.

41 Definido por la Real Academia como "causar o infundir miedo".

42 En este sentido, RAMÓN RIBAS, E.: "La intimidación en los delitos sexuales entre las agresiones y los abusos sexuales" en VVAA: La Manada. Un antes y un después en la regulación de los delitos sexuales en España", Valencia, 2018, p.147.

43 TOL5.185.905

44 Esta es la tesis que sostiene CUERDA ARNAU en la determinación del alcance de la intimidación, si bien en el ámbito del tipo de agresión sexual. CUERDA ARNAU, M.L.: "Agresión y abuso sexual: violencia o intimidación vs consentimiento viciado" en VVAA: La Manada. Un antes y un después en la regulación de los delitos sexuales en España", Valencia, 2018, p. 111.

45 Dicha perspectiva la tiene en cuenta RAMÓN RIBAS para considerar que en el caso de la Manada existió la intimidación requerida en el delito de agresión sexual, conclusión que a su juicio debería haberse llegado incluso sin adoptar dicha perspectiva; ob. cit., pá.163. 
Como dijimos, resulta frecuente emplear medios distintos para llevar a cabo alguna de las acciones descritas. Así, valga como ejemplo la sentencia de 3 diciembre de 2013 en la que el Tribunal Supremo examinó un caso en que se apreció la captación y traslado coactivo, mediante violencia e intimidación: " $l a$ víctima recibió en Rumania un puñetazo y fue introducida a la fuerza en un taxi, trasladada en un avión desde Bucarest a España acompañada de una persona que le decía que en caso de que intentara escapar tirarían a su hijo por la ventana"46.

También resulta frecuente la "trata fraudulenta": el engaño es una de las formas más comunes utilizadas para la finalidad de explotación laboral ${ }^{47}$, por ejemplo, reclutar a la víctima engañándola sobre el tipo de trabajo que van a realizar, sobre las condiciones de vida o de trabajo en el lugar de destino o prometiéndoles la búsqueda de un trabajo o la regularización de su situación si son extranjeras. El engaño ha de ser bastante y eficaz para anular o disminuir la voluntad de la víctima (SAP Valencia 25 octubre 2010). Valga también como ejemplo la SAP de Baleares de 1 septiembre 2017 que condenó a los acusados como autores criminalmente responsables de dos delitos de trata de seres humanos y otro de maltrato de obra, siendo la primera víctima engañada al decirle que tendría un trabajo legal en el que obtendría una importante cantidad de dinero. Los tratantes se quedaban con casi todo el dinero, daban alojamiento y comida a la víctima. El que no huyesen se explica por el miedo al maltrato, las amenazas que sufrían y su desarraigo. Ambas víctimas fueron conminadas a ejercer la mendicidad, anunciándoles palizas y agresiones si no traían suficiente dinero, controlando los alimentos que cogían de la casa, registrando sus ropas, no permitiéndoles ninguna disponibilidad económica, siendo agredidas físicamente y controladas mediante un móvil que no les permitía efectuar llamadas ${ }^{48}$.

46 TOL4.038.162

47 Cfr. Informe ACCEM: La trata de personas con fines de explotación laboral. Un estudio acerca de la realidad en España, 2006

48 TOL6.378.895 


\section{El abuso de situación de superioridad o necesidad o}

de vulnerabilidad de la víctima como medio comisivo ha sido una de las modificaciones introducidas en la reforma del CP de 2015, motivada por la Directiva 2011. El legislador español ha optado por llevar a cabo una interpretación auténtica de la denominada "trata abusiva" lo que resulta saludable para mejorar la taxatividad de los preceptos penales.: "Existe una situación de necesidad o vulnerabilidad cuando la persona en cuestión no tiene otra alternativa, real o aceptable, que someterse al abuso" (177 bis.1. in fine $)^{49}$.

Tanto la normativa europea como la jurisprudencia ha reflejado expresamente la especial vulnerabilidad de mujeres y niñas, particularmente en el caso de trata con fines de explotación sexual. La raíz del problema es por todos conocida y se

49 De interés en relación a la ocupación de mano de obra bajo engaño o abuso de vulnerabilidad la STS de 28 de septiembre de 2017, desestimó el recurso de casación, conformando la sentencia condenatoria que consideró acreditada la comisión de un delito contra los derechos de los trabajadores previsto en el art. $311.1 \mathrm{CP}$ :

"Los trabajadores son privados del derecho básico y elemental de todo trabajador: el descanso semanal. No es una mera cuestión económica. Dicha imposición ilegal sólo se entiende por la vulnerabilidad de los trabajadores que no son meramente desempleados sino inmigrantes marroquies que realizaban labores de pastoreo, que no tenían arraigo, no conocían el idioma y con bajo nivel cultural. La vulnerabilidad es es el caldo de cultivo idóneo para que una sutil presión cancele derechos laborales.... "La situación de necesidad está definida en el delito de trata. En abstracto siempre existirá otra alternativa que la de someterse a un abuso, pero se trata de valorar en concreto si podia exigirse razonablemente a la víctima seguir un camino distinto a la aceptación resignada a la explotación. No basta con indicar alternativas si estas no son viables, atendidas las circunstancias de la víctima $y$ de los hechos. El que las víctimas hayan denunciado, no significa que no existiera una situación de necesidad. Una mayor capacidad de rebelión frente a las condiciones injustas derivada del paso del tiempo y el mayor arraigo que van adquiriendo no borra el carácter penal de los hechos denunciados. La situación de necesidad debe ser valorada "ex ante".... "Es razonable para fijar la responsabilidad civil establecer como baremo el de la retribución que se hubiera debido recibir por los días de descanso que las Autoridades policiales y judiciales trabajan de manera incansable en la lucha contra esta lacra, considerada como la esclavitud del siglo XXI." 
sitúa, como bien explica SANZ MULAS, en la aún extendida concepción de la mujer como inferior al hombre y la necesidad de su sometimiento limitando sus capacidades, sobre todo las sexuales. Si dicha situación es preocupante, todavía se recrudece más aún en el caso de la mujer inmigrante, siendo la diversidad cultural un factor de riesgo ${ }^{50}$. A modo de ejemplo, la SAP Valencia de 21 de junio de 2018 refleja en un supuesto de delito de trata en concurso medial con uno de prostitución, que "se da una situación de vulnerabilidad por ser extranjeras jóvenes que no conocen ni el idioma y, además, condiciones abusivas al quedarse con el importe de la mitad de los servicios"51. Incide también en el abuso de superioridad y vulnerabilidad de la víctima la STS de 4 de febrero de $2014^{52}$ en un supuesto en que los condenados, prima de la víctima y su novio, convencieron a la menor para que abandonase el Centro de Protección de Menores en Italia en el que se encontraba, y se trasladase a Barcelona, con documentación falsa; una vez allí la dedicaron durante varias semanas a la prostitución callejera.

Por último, la entrega o recepción de pagos o beneficios para lograr el consentimiento de la persona que poseyera el control sobre la víctima también es un medio introducido por la reforma penal de 2015, englobando tanto los supuestos que tienen su causa en el pleno sometimiento de la víctima al padre, marido, patriarca o líder comunitario en diversas culturas, como también aquellos casos donde la víctima se encuentre previamente tratada.

No obstante, debe advertirse que en el caso de víctimas menores de edad se considerará que concurre el delito de trata cuando se lleven a cabo cualquiera de las acciones típicas, no siendo necesario que se recurra en este caso a ninguno de los medios mencionados (177 bis 2.). Por su parte, el 177 bis 3 .

50 SANZ MULAS, N.: Delitos culturalmente motivados, Valencia, 2018, p. 131.

51 TOL 6.677.227

52 TOL4.110.012 
precisa que, el consentimiento de la víctima de trata será irrelevante, cuando se haya recurrido a alguno de los medios descritos en el apartado primero del artículo. A este respecto, nuestro Tribunal Supremo ha dejado claro que, aunque la víctima sepa que el tratante la va a prostituir y explotar y aún así no rechace su traslado a España, estamos ante un medio comisivo de abuso de una situación de vulnerabilidad ${ }^{53}$.

\subsection{Las finalidades del delito de trata.}

Las modalidades de conductas descritas deben llevarse a cabo con alguna/s de las finalidades que enumera el legislador, todas identificadas con "fines de explotación" de las víctimas: el legislador español, adecuándose al marco europeo, tipifica la trata para fines de explotación laboral, sexual, para realizar actividades delictivas, para extraer órganos corporales o para realizar matrimonios forzados. En el presente trabajo voy a detenerme en los supuestos de trata con fines de explotación laboral y trata sexual, donde reside el mayor porcentaje de víctimas de este delito, como ya se mencionó.

Dichos fines constituyen elementos subjetivos del tipo de acción y su ausencia determinaría la inexistencia del delito de trata, dado que desempeñan un papel definitorio de la acción descrita, configurando lo que VIVES ANTÓN denomina intencionalidad objetiva. Como todo delito descrito con elementos subjetivos debe tenerse presente que jamás podrá cometerse por imprudencia: el delito es doloso, de manera que si el sujeto desconoce la finalidad de su acción (captar, transportar...) no incurrirá en la responsabilidad del art. 177 pero sí, si una vez iniciada tiene conocimiento y continua con la acción ${ }^{54}$.

Ya adelantamos, que la explotación efectiva de la víctima no forma parte de la conducta típica, no es necesaria para la

53 Así la STS de 18 de mayo de 2016 (TOL 5.734.608).

54 CUERDA ARNAU, M.L.: "Torturas y otros delitos contra la integridad moral. Trata de seres humanos" en Derecho Penal.Parte.Especial, Valencia, 2015, p.195. 
consumación de la trata, basta con que se actúe con alguna de las finalidades descritas. Sean una o varias finalidades habrá un solo delito de trata, sin perjuicio de que puedan surgir concursos de delitos, en el caso de materializarse la explotación laboral o sexual.

A) La "imposición de trabajos forzados o prácticas similares a la esclavitud $o$ a la servidumbre o a la mendicidad" constituye la primera de las finalidades del delito de trata, sin embargo el art. 177 bis de nuestro Código Penal no recoge un concepto de "esclavitud", teniendo que acudirse a los delitos de lesa humanidad (art.607 bis $2.10^{\circ}$ ) que sí lo prevén: "Por esclavitud se entenderá la situación de la persona sobre la que otro ejerce, incluso de hecho, todos o algunos de los atributos del derecho de propiedad, como comprarla, venderla, prestarla o darla en trueque". Esto es, supone el estado o condición de un individuo sobre el cual se ejercitan los atributos inherentes al derecho de propiedad o algunos de ellos ${ }^{55}$.

De manera que la finalidad de la trata puede ser, tanto para realizar las labores más penosas que ofrecen nuestros mercados de trabajo -en condiciones de sometimiento- como, simplemente, para realizar trabajos domésticos desde una posición de servidumbre. De acuerdo con la definición recogida en el Convenio n.29 de la OIT sobre trabajo forzoso de 1930 "todo trabajo o servicio exigido a un individuo mediante amenaza de una pena cualquiera y para el cual el individuo no se ofrece voluntariamente" (art. 2 párrafo.1)

A efectos del delito de trata y desde una concepción contemporánea del término, debe revelar una vinculación de carácter laboral en sentido amplio y más que basarse en los derechos de propiedad sobre la persona, en una relación posesoria de carácter fáctico, donde el autor se apropie ilícitamente del traba-

55 Art. 1.1. Convención de Ginebra sobre la esclavitud de 1926; art. 7 Convención suplementaria sobre la abolición de la esclavitud, la trata de esclavos y las instituciones o prácticas análogas a la esclavitud de 1956; art. 7.2 del Estatuto de Roma de la Corte Penal Internacional de 1988. 
jo de la víctima, comportándose como si tuviera un derecho de disposición sobre ella ${ }^{56}$. Desgraciadamente, el trabajo forzado no es un asunto del pasado, ni siquiera en Europa. De hecho, varios Estados del Consejo de Europa (miembros del Convenio Europeo para la protección de los Derechos Humanos y de las Libertades Fundamentales (CEDH) ya han sido condenados por el Tribunal Europeo de Derechos Humanos (TEDH) por violar el articulo 4 del Convenio Europeo $\mathrm{DH}^{57}$, el cual establece que:

1. "Nadie podrá ser sometido a esclavitud o servidumbre.

2. Nadie podrá ser constreñido a realizar un trabajo forzado u obligatorio

Recordemos que aunque es la trata con fines de explotación sexual la que afecta mayoritariamente a mujeres y niñas, también se producen explotación laboral de las mismas en sectores como es el empleo del hogar, la agricultura o los matrimonios forzados. Es por ello que desde la doctrina hay voces que tratan de reformular un concepto amplio de «violencia de género laboral», con objeto de visibilizar las diferentes manifestaciones de violencia machista habidas en la esfera de las relaciones laborales que, a menudo, quedan fuera del concepto comúnmente aceptado $^{58}$.

En este contexto resulta obligada la cita de la sentencia de la Corte Europea de Derechos Humanos (caso Siliadin contra Francia de 26 de julio de 2005). Las circunstancias del caso fueron las siguientes: la demandante llegó a Francia desde Togo con 15 años con una persona que había acordado con su padre: que iba a trabajar hasta reembolsar el pasaje aéreo, que su condición de inmigrante se iba a regularizar y que la enviarían

56 POMARES CINTA, E: "El delito de trata de seres humanos con finalidad de explotación laboral" en RECPC, 2011, p. 19.

57 Vid. Referencias jurisprudenciales en FERNÁNDEZ BURGUEÑO: Análisis crítico de la jurisprudencia de la Corte Europea art. 4, 2017.

58 ESPEJO MEJÍAS, P.: Hacia una reformulación de la violencia de género laboral, Madrid 2018

Estudios Penales y Criminoiógicos,

vol. XXXIX (2019). ISSN $1137-7550:$ 589-642 -198- hitp://dx.doi.org/10.15304/epc.39.5760 
al colegio. En realidad, la demandante trabajó para esa persona durante algunos meses, antes de ser "prestada" a un matrimonio en cuya casa trabajó sin descanso durante 15 horas diarias, sin días libres, durante varios años, sin recibir sueldo, sin ir al colegio, sin documentos de identidad, durmiendo en un colchón en la habitación de los hijos. En sus alegaciones la demandante hace referencia a los convenios internacionales sobre el tema, asi como a los criterios estipulados por Naciones Unidas y Consejo de Europa para determinar el significado e "identificar las formas modernas de esclavitud y servidumbre" muy relacionadas con el tráfico de seres humanos, la servidumbre y el trabajo forzado u obligatorio (...). De suerte que considera que, en todo caso "esa entrega por parte de un padre mediante falsas promesas, con el fin de explotar su trabajo, era asimilable a una práctica análoga a la esclavitud" y que en realidad era "una esclava doméstica que había sido reclutada en África". Y finaliza la demandante denunciando como en el Code Penal francés no había delitos específicos de esclavitud o trabajos forzados y como la falta de criterios legales que permitan que los tribunales determinen si dicha situación existía determinaba interpretaciones excesivamente restrictivas. En vista de lo expuesto la Corte consideró que la demandante, como mínimo, fue sometida a trabajo forzoso en los términos del art. 4 del Convenio Europeo cuando era menor de edad, sosteniendo que hubo violación del citado precepto.

B) El apartado b) del n.1 del art. 177 bis del CP se refiere a la trata con fines de explotación sexual, incluida la pornografía. Según Naciones Unidas, “....si bien en el Protocolo [contra la trata de personas] se distingue entre la explotación por trabajos o servicios forzados y la explotación sexual, ello no debe llevar a la conclusión de que la explotación sexual coercitiva no equivale a trabajos o servicios forzados, especialmente en el contexto de la trata de personas. La explotación sexual coercitiva y la prostitución forzada están circunscritos al ámbito de la definición del trabajo forzoso o el trabajo obligatorio. 
Desde que entró en vigor el Convenio sobre el trabajo forzoso de 1930, la Comisión de Expertos de la OIT ha considerado la trata con fines de explotación sexual y comercial una de las formas de trabajo forzoso" 59 . Aún así, no existe un consenso que permita identificar terminológicamente la finalidad de explotación sexual como modalidad específica de servicios forzados. Estas deficiencias terminológicas se trasladan a la explotación laboral, en el contexto de la trata (Comunicación de la Comisión Europea sobre la Estrategia de la Unión Europea para la erradicación de la trata de seres humanos (2012-2016).

Para arrojar claridad en la materia resulta conveniente analizar como está siendo interpretada por la jurisprudencia española la finalidad de explotación sexual en el contexto de la trata y qué criterios se utilizan para acreditar dicha finalidad explotadora. Un ejemplo es el supuesto de la STS de 13 de mayo de 2015 (TOL5.004.273) en el que la Sala incide en la complejidad de la definición de la explotación y la necesidad de que "el relato de los hechos probados sea lo suficientemente descriptivo como para descartar el riesgo de menoscabo del principio de tipicidad". Recuerda el TS que el delito de trata es de tendencia y consumación anticipada por cuanto "basta realizar la acción descrita con un dolo preordenado a alguno de aquellos fines para la consumación del delito". Pese a ello concluye que era preciso dejar claro que el propósito del sujeto activo era realizar repetidamente actos de agresión y abuso sexual sobre la víctima, no considerando acreditado en el caso resuelto el fin de la explotación, al no quedar demostrado que existiera una vocación de sistematicidad. En mi opinión, la sistematicidad sí se desprende

59 Una situación de trabajo forzoso está determinada por la naturaleza de la relación existente entre una persona y un "empleador", y no por el tipo de actividad realizada, la legalidad o ilegalidad de la actividad en virtud de la legislación nacional, o su reconocimiento como "actividad económica. Vid. Documento del Grupo de trabajo sobre la trata de personas establecido por la Conferencia de las Partes en la Convención de las Naciones Unidas contra la Delincuencia Organizada Transnacional, en https://www.unodc.org/documents/treaties/organized_crime/CTOC_COP_WG_4_2010_2_S.pdf

Estudios Penales y CRIMINológicos,

vol. XXXIX (2019). ISSN 1137-7550: 589-642 -200- hitp://dx.doi.org/10.15304/epc.39.5760 
de los hechos probados ${ }^{60}$, al quedar acreditado que el acusado quería que viniese a España para tenerla a su disposición con miras a mantener relaciones sexuales con ella siempre que lo desease, plan que ocultó a la víctima", llegando a atentar sexualmente contra ella en una ocasión.

Otra sentencia de interés es la STS de 29 de marzo de 2017 (TOL6.026.830) la cual declaró no haber lugar al recurso de casación interpuesto contra la sentencia condenatoria de la AP de Valencia por delito de trata para explotación sexual e inmigración ilegal, indicando que: "La trata de seres humanos con destino a la explotación sexual, cosifica a las mujeres víctimas y las humilla y veja con toda clase de maltratos, incluida la violencia, la agresión sexual y, si llega a plantearse, el aborto forzado".

Por consiguiente, me sumo a las voces que consideran que las víctimas de trata sexual son también víctimas de violencia de género, tanto atendiendo a los instrumentos e informes internacionales citados como también a su realidad criminológica, dado que se obtiene, como ya expusimos, en un contexto de violencia física, psicológica y sexual o bajo amenazas no solo a ellas sino incluso también a sus familiares ${ }^{61}$.

En esta dirección, el ya citado Plan integral de lucha contra la trata de mujeres y niñas con fines de explotación sexual (2015-18) elaborado por el Ministerio de Sanidad, Servicios Sociales e Igualdad considera expresamente esta modalidad "una forma de violencia de mujer"62. De ahí la importancia de que la futura Ley integral contra la trata proponga que las mujeres víctimas de trata sean catalogadas como víctimas de violencia de género, lo que implicaría que pudieran acogerse a los mismos

60 Concordante con la expuesta por LAFONT NICUESA: "El delito de trata de seres humanos en la jurisprudencia del TS" en PÉREZ ALONSO, E. (Dir.): $E l$ derecho ante las formas contemporáneas de esclavitud, Valencia, 2017, p. 476.

61 En este sentido, ORBEGOZO, I.: ob. cit., p. 634 y ss.

$62 \mathrm{http} / /$ www.violenciagenero.igualdad.mpr.gob.es/planActuacion/planContraExplotacionSexual/docs/Plan_Integral Trata 18 Septiembre2015_2018.pdf, pág.9. 
recursos que las víctimas de maltrato, tales como casa de acogida $o$ atención psicológica.

\section{El sujeto pasivo y la excusa absolutoria del 177 bis}

\section{1: el doble rol de la mujer víctima de trata.}

Como ya dijimos, aunque la trata afecta tanto a hombres como a mujeres, no es un fenómeno objetivamente neutro en cuanto al género, toda vez que las mujeres y niñas son las principales víctimas. El sujeto pasivo tampoco está determinado por la nacionalidad (el Preámbulo de la LO 2010 se refiere a "víctima nacional o extranjera") sin embargo, la realidad criminológica nos muestra que en su gran mayoría afecta a mujeres extranjeras. Pues bien, resulta frecuente que se obligue a la víctima a colaborar con la organización, bien llevando a cabo actividades de vigilancia y control sobre otras víctimas, de manera que acaba convirtiéndose en víctima y tratante, o que se las utilice para el traslado de sustancias estupefacientes o para la comisión de delitos patrimoniales. Así, por ejemplo, la forma de llevarse a cabo la captación de algunas mujeres subsaharianas en ocasiones se realiza por víctimas de su misma nacionalidad e incluso de su misma familia, a cambio de ser liberadas. En este caso la víctima de trata despliega también un rol de tratante.

Es por ello que se traslada al derecho español la previsión contenida en el art. 8 de la Directiva 36/2011 conforme al cual los Estados miembros adoptarán las medidas necesarias para garantizar que las autoridades nacionales competentes puedan optar por no enjuiciar ni imponer penas a las víctimas de trata por su participación en actividades ilícitas que se hayan visto obligadas a cometer como consecuencia directa de haber sido objeto de alguno de los actos del art.2. En particular, en el apartado 11 del art. 177 bis del CP español se prevé la exención de la pena en estos casos "por las infracciones cometidas mientras haya estado en situación de explotación, siempre que se pruebe que su participación ha sido consecuencia directa de la situación de violencia, intimidación o engaño a la que se le sometió y que exista una adecuada proporcionalidad entre dicha 
situación y el hecho criminal realizado". Dicha exención que tiene naturaleza de "excusa absolutoria" pretende potenciar la denuncia y que intervengan como testigos en el proceso ${ }^{63}$, así

63 En el ámbito del Derecho Administrativo, con el objeto de buscar la colaboración contra las redes organizadas, la legislación española de extranjería (LO 4/2000, de 11 de enero, sobre derechos y libertades de los extranjeros en España y su integración socia) cuenta con un especial régimen de protección de las víctimas de trata:

Art. 59.1.El extranjero que se encuentre irregularmente en España y sea víctima, perjudicado o testigo de un acto de tráfico ilícito de seres humanos, inmigración ilegal, explotación laboral o de tráfico ilícito de mano de obra o de explotación en la prostitución abusando de su situación de necesidad, podrá quedar exento de responsabilidad administrativa y no será expulsado si denuncia a los autores o cooperadores de dicho tráfico, o coopera y colabora con las autoridades competentes, proporcionando datos esenciales o testificando, en su caso, en el proceso correspondiente contra aquellos autores.

El apartado 2 del artículo 59 bis de la Ley Orgánica 4/2000, se modifica por LO 8/2015 el que queda redactado en los siguientes términos:

«2. Los órganos administrativos competentes, cuando estimen que existen motivos razonables para creer que una persona extranjera en situación irregular ha sido víctima de trata de seres humanos, informarán a la persona interesada sobre las previsiones del presente artículo y elevarán a la autoridad competente para su resolución la oportuna propuesta sobre la concesión de un período de restablecimiento y reflexión, de acuerdo con el procedimiento previsto reglamentariamente.

Dicho periodo de restablecimiento y reflexión tendrá una duración de, al menos, noventa dias, y deberá ser suficiente para que la víctima pueda decidir si desea cooperar con las autoridades en la investigación del delito y, en su caso, en el procedimiento penal. Tanto durante la fase de identificación de las víctimas, como durante el periodo de restablecimiento y reflexión, no se incoará un expediente sancionador por infracción del artículo 53.1.a) y se suspenderá el expediente administrativo sancionador que se le hubiere incoado o, en su caso, la ejecución de la expulsión o devolución eventualmente acordadas. Asimismo, durante el periodo de restablecimiento y reflexión, se le autorizará la estancia temporal y las administraciones competentes velarán por la subsistencia y, de resultar necesario, la seguridady protección de la víctima y de sus hijos menores de edad o con discapacidad, que se encuentren en España en el momento de la identificación, a quienes se harán extensivas las previsiones del apartado 4 del presente artículo en relación con el retorno asistido o la autorización de residencia, y en su caso trabajo, si fueren mayores de 16 años, por circunstancias excepcionales. Finalizado el periodo de reflexión las administraciones públicas competentes realizarán una evaluación de la situación personal de la víctima a efectos de determinar una posible ampliación del citado periodo. 
como permite salvar los obstáculos que se plantean cuando no concurren la totalidad de los requisitos para apreciar un estado de necesidad o una situación de miedo insuperable en la víctima en los supuestos descritos.

Pese a ello estudios criminológicos sacan a la luz supuestos donde a víctima de delito de trata sufre un proceso de doble victimización, de un lado ante las dificultades de ser identificada como víctima de este fenómeno y por tanto, sin posibilidad de acceso a los derechos que le corresponden como víctima de dicho delito y de otro lado, al llegar a ser condenada por un delito cometido en fase de explotación ${ }^{64}$. A este respecto autoras como VILLACAMPA, TORRES ${ }^{65}$ y FARALDO ${ }^{66}$ destacan que, entre los obstáculos a la identificación de las víctimas de trata, el foco centrado en las víctimas de trata para explotación sexual invisibiliza otras como las víctimas de trata laboral e incluso a los hombres y niños víctimas de trata.

\section{Penalidad y cuestiones concursales}

El tipo básico de trata tiene prevista en el CP una pena de prisión de cinco a ocho años de prisión, previéndose ulteriores agravaciones por la condición del sujeto activo (prevaliéndose de su condición de autoridad o funcionario público), por la pertenencia a una organización o para dispensar una mayor protección a la víctima (por ser menor de edad, especialmente vulnerable o por ponerse en peligro su vida o integridad física).

64 En cuanto a la dinámica comisiva de los delitos, VILLACAMPA ESTIARTE/ TORRES ROSELL sistematizan los supuestos en dos: atendiendo a que las mujeres fueron empleadas para la comisión de un delito de tráfico de drogas o bien fueron utilizadas para la comisión de delitos patrimoniales: "Mujeres víctimas de trata en prisión en España", en Revista de Derecho Penal y Criminología, julio 2011, p. 415 y ss.

65 Ob. cit, p. 488

66 FARALDO CABANAS, P. "Donde están las víctimas de trata? Obstáculos a la identificación de las mujeres víctimas de trata en España", en Libro de Actas Conferencia Internacional "Día europeo contra el tráfico de seres humanos", octubre 2017. 
Como novedad introducida por la reforma penal de 2015 debe valorarse positivamente la introducción del delito de trata en el art. $57 \mathrm{CP}$ como uno de los delitos por los se permite la imposición de las penas de alejamiento del art. $48 \mathrm{CP}$.

En un principio, las primeras sentencias de 2012 discutían la configuración del delito de trata, esto es, si habían tantos delitos como víctimas o si el sujeto era plural. Por Acuerdo Plenario de 31 de mayo de 2016 el TS adoptó una decisión por unanimidad en su sentencia 538/2016: el delito de trata de seres humanos es un delito que contempla un sujeto pasivo individual y no plural y que, por tanto, obliga a sancionar tantos delitos como víctimas, con arreglo a las normas que regulan el concurso real. Recordemos que el bien jurídico protegido es la dignidad humana, que no es un concepto global sino individual.

En aplicación del citado Acuerdo, la STS 17 de junio de 2016 fue la primera en rechaza la posibilidad de aplicar el delito de trata en concurso ideal pluriofensivo y en continuidad delictiva en el caso de existencia de varias víctimas ${ }^{67}$. El delito de trata de seres humanos tiene un sujeto pasivo individual, y no plural. Del mismo modo se pronuncian, entre otras, las SSTS 3 de marzo de 2016 y 23 de marzo de $2017^{68}$.

Por tanto, las penas del delito de trata se impondrán, sin perjuicio de las que correspondan, recurriendo a las reglas concursales para valorar el daño a otros bienes jurídicos, según lo dispuesto en el art.177 9. CP. Por ejemplo si como dijimos, la explotación sexual coercitiva y la prostitución forzada están circunscritos al ámbito de la definición del trabajo forzoso, cuando

67 La primera sentencia a la que se ha aplicado este criterio dobla la condena -de 5 años y 6 meses de prisión a 10 años y 7 meses- para cada uno de los dos acusados de traer a España a dos ciudadanas nigerianas a las que prometieron que iban a trabajar en Tenerife como peluqueras. Una vez allí, sin embargo, les dijeron que tenían que ejercer la prostitución para saldar la deuda que habían contraído con ellos -4.000 euros cada una-, al tiempo que las amedrentaban y presionaban para que aceptaran las condiciones impuestas.

68 TOL5.679.546 y TOL6.026.687 
aquella se materialice hay voces que apuntan a resolverlo como un concurso de delitos entre el de prostitución coactiva (variando la pena en función de si la víctima es mayor o menor de edad) y el delito laboral de que se trate (art. 311 y ss CP) ${ }^{69}$.

En todo caso, el ánimo de lucro es consustancial a la explotación sexual y en consecuencia, si ésta se lleva efectivamente a cabo a través de la prostitución coactiva, el delito de trata entrará en concurso con el delito del art.187 del CP (en el caso de mayores de edad) o con el art. $188 \mathrm{CP}$ (si se tratara de menores). La reciente jurisprudencia viene entendiendo que el delito de trata es el medio necesario para la realización de la explotación, lo que nos avoca a un concurso medial, como así estiman, entre otras las SSTS de 20 de octubre de 2016 y de 8 de abril de $2016^{70}$. No obstante se plantea una situación paradójica puesto que hay una ausencia de correspondencia de las penas con la gravedad del injusto: los delitos a través de los cuales se manifiesta la explotación de la víctima de trata son castigados con penas sensiblemente inferiores que el delito de trata en si, que en definitiva supone el proceso hacia la esclavización y el mantenimiento de la explotación ${ }^{71}$. Afirma con razón MAQUEDA como con ello queda interrumpida la idea de proceso y la relación de progresión existente en sus diferentes fases, de la trata a la explotación, "perdiendo de vista la gravedad de ese último estado de sujeción límite en que queda la víctima bajo la relación de dominio de sus explotadores" $" 72$.

En los supuestos en que la explotación laboral conlleva una situación de ataque a la dignidad de la víctima, al no existir una figura específica, queda el recurso de aplicar, además el de-

69 POMARES CINTAS: ob. cit. p.137

70 TOL5.856.563 y TOL5.691.275

71 Frente a la pena de cinco a ocho años de prisión del delito de trata, la explotación sexual en forma de determinación coactiva a la prostitución (art. 187.1) tiene asignada una pena de dos a cinco años y multa, y la explotación laboral del art. $311 \mathrm{CP}$ una pena que va de seis meses a seis años y multa.

72 MAQUEDAABREU: "Trata y esclavitud no son lo mismo pero, ¿qué son", cit., p. 1255. Así también, VILLACAMPA, El delito de trata...ob. cit.,p. 465. 
lito de trato degradante del $173.1 \mathrm{y}$, eventualmente, el de detención ilegal, si se constata el encierro ${ }^{73}$.

\section{Consideraciones no conclusivas: de la vulnerabilidad al empoderamiento}

Como ha sido puesto de manifiesto, el fenómeno de la trata y la esclavitud moderna representa unos de los retos más complejos y crecientes del mundo contemporáneo y una de las formas más atroces de violencia contra la mujer. Conscientes de lo mucho que queda por hacer y para una completa implementación del Convenio del Consejo de Europa sobre la lucha contra la trata de seres humanos, concordamos con el Pacto de Estado contra la violencia de género ${ }^{74}$ en la necesidad de aprobar una Ley integral contra la trata de personas ${ }^{75}$. Una respuesta legal integral y multidisciplinar, no centrada exclusivamente en la trata con finalidad de explotación sexual, sino que incluya las demás formas de explotación ${ }^{76}$. Adicionalmente, partiendo de las diferencias ya expuestas en los procedimientos de captación, dominación, control y vigilancia de las víctimas, dicho marco legal basado en los derechos humanos requiere además una perspectiva de género, en coherencia con el Convenio de Estambul, tal y como proponen las instituciones internacionales y en nuestro país recientemente el Grupo de Trabajo multidisciplinar creado por acuerdo de la Comisión Permanente del Consejo General del Poder Judicial. Como se ha reflejado, la especial vulnerabilidad de mujeres y niñas en contextos donde impera la violencia contra las mujeres y las desigualdades de género (económicas, sociales, formativas...) es la raíz primordial de la trata sexual.

73 Entre las más recientes, STS de 24 de marzo de 2017 (TOL 6026687).

$74 \mathrm{Al}$ respecto, el Informe de la Ponencia del Senado, dedica las medidas 157 a 160 a desglosar esta idea.

75 Término más sencillo y en consonancia con el vocablo utilizado por Naciones Unidas en la Ley Modelo contra la trata de personas https://www.unodc. org/documents/human-trafficking/TIP-Model-Law-Spanish.pdf

76 Sobre este particular, véase, FARALDO CABANAS, ob. cit., p. 150. 
Ahora bien, la ley integral ha de cubrir todas las víctimas, no invisibilizando a hombres y niños víctimas de explotación laboral que también requieren recursos especializados.

En particular, desde un abordaje contemporáneo de este delito se considera insuficiente e ineficaz la mera aplicación de las disposiciones incriminadoras, y por tanto debe desarrollarse una estrategia nacional que desplace el centro de gravedad en la lucha contra la trata a la prevención y a la protección a la víctima $^{77}$, intensificando la cooperación internacional a través de convenios de colaboración con los países de origen y con medidas diferenciadas en función del género y del tipo de trata: junto a una eficaz intervención penal, debe cubrirse tanto la prevención -atender a las causas de fondo, incrementando las oportunidades de migración legal, fomentando la cooperación estatal, la investigación y la formación ${ }^{78}$ de los profesionales que pueden entrar en contacto con las víctimas- cuanto la protección y asistencia a las víctimas adaptada a sus necesidades (proporcionar alojamiento seguro, orientación psicológica, programas de protección y reinserción social de las mujeres afectadas, oportunidades de empleo...). Son necesarios más y mejores recursos para que las víctimas puedan declarar desde la libertad y para una investigación multidisciplinar que pueda combatir las redes organizadas. En este sentido, debería contemplarse un sistema de protección de las víctimas de trata en la línea de lo diseñado para las víctimas de violencia de género ${ }^{79}$. Ahora bien,

77 En la línea de lo que se conoce, desde la aprobación del Protocolo de Palermo a principios del siglo XX1, como Política 3P. Vid. in extenso, VILLACAMPA: "El delito de trata de seres humanos en Derecho español tras la reforma de 2015, en El Derecho ante las formas contemporáneas de esclavitud, 2017, p. 448 y ss

78 En declaraciones del Fiscal de la Sala de Extranjería señalaba como "Desde los planes de formación, la lucha contra la esclavitud requiere de una superespecialización, tenemos que saber hasta Derecho subsahariano".

79 Puede verse sobre este particular la propuesta de lege ferenda de RUEDA VALDIVIA, en "Hacia un nuevo sistema de protección de las víctimas de trata en derecho español" en El Derecho ante las formas contemporáneas de esclavitud, ob. cit., p. 911. Lo cierto es que, como ha afirmado GARRIDO 
la intervención con unas y otras ha de ser distinta: el proceso de trata es distinto al de la violencia de género en el ámbito de la pareja y por extensión la situación en que se encuentra la víctima al ser rescatada, por lo que el empoderamiento de la víctima de trata se ha de dirigir a diferentes ámbitos, es mucho más amplio.

Previamente es necesario reforzar el proceso de identificación de las víctimas de trata ${ }^{80}$, la cual constituye la puerta de entrada a otros derechos, de ahí la relevancia de la formación específica en la materia de los cuerpos policiales y judiciales. Por otra parte, resulta también de vital importancia generalizar el uso de mecanismos procesales adecuados, como la denominada "prueba preconstituida" de la declaración de la víctima, para evitar su desaparición y la incomparecencia judicial motivada por el temor a las eventuales consecuencias de una declaración. En definitiva, evitando que durante el proceso se produzca una segunda victimización. Esa justicia de género debiera tener en consideración la interesante vía propuesta en la STSJ de Palmas de Gran Canarias de 7 de marzo de 2017 (Sala de lo Social) ${ }^{81}$ por la que "en todos los casos que involucren relaciones asimétricas, prejuicios y patrones estereotípicos por razón de género, deberá aplicarse en la impartición de justicia una metodología de análisis integradora de la perspectiva de género" $"$.

JIMÉNEZ, si bien la trata ha recibido atención desde el ámbito penal, ha sido deficiente su tratamiento como forma de violencia específica sobre la mujer, "esto es, ha adolecido de la perspectiva de género"Comparecencia en el Senado, Ponencia de estudio para la elaboración de estrategias contra la violencia de género, 4 agosto 2017.

80 En la actualidad los aspectos relativos a la identificación y protección de las víctimas se contienen en el Protocolo Marco de actuación de víctimas de trata de 2014 suscrito por la Fiscalía General del Estado, Consejo General del Poder Judicial y Administración General del Estado. Vid. al respecto, LAFONT NICUESA, L.: "Directrices básicas sobre la regulación de los delitos de trata de seres humanos en España" en PÉREZ ALONSO/ POMARES CINTAS (Coord): La trata de seres humanos en el contexto penal iberoamericano, 2019 , p. 347 y ss

81 TOL6.000.687

82 En definitiva, como acertadamente señala ACALE, las nuevas formas de violencia de género y sus necesarios ajustes en el Código Penal fundamen- 
Adicionalmente, respecto a los retos que esta realidad supone para el Derecho Penal, desde el punto de vista de técnica legislativa consideramos que tendría que regularse conjuntamente el delito de trata y la esclavitud ${ }^{83}$, en un Título específico que llevara por rúbrica "De la trata y la explotación de personas", en consonancia con lo previsto en otros países, como Alemania, Francia Italia y Reino Unido ${ }^{84}$, donde sí han dado respuesta a las exigencias internacionales.

No existe en nuestro ordenamiento una figura específica en relación a la "imposición de trabajos forzados o servicios en régimen de esclavitud (salvo la figura de utilización de menores para mendicidad art.232); por ello sería una opción legislativa recomendable, dando así cumplimiento a los requerimientos internacionales, ofrecer una respuesta punitiva razonable a las formas contemporáneas de esclavitud, constituyendo tipos penales

talmente tienen en consideración el derecho que tienen las mujeres víctimas de esta clase de violencia de recibir una respuesta coherente por parte del ordenamiento jurídico ACALE SÁNCHEZ, M.: "Derecho penal y violencia de género: ¿un nuevo cambio de paradigma?" en MARTÍN SÁNCHEZ (Dir): Estudio integral de la violencia de género, Valencia, 2018 p. 439.

83 La doctrina española de manera creciente viene criticando la incoherencia legislativa antes expuesta, en relación a la falta de espacio penal propio para incriminar los delitos de explotación y el atentado que representan para los derechos humanos de las víctimas, como recuerda MAQUEDA ABREU: ob. cit.p. 1256.

84 El Código Penal alemán regula en los delitos contra la libertad personal (Sección 18 de la Parte Especial) la trata de personas y las demás formas de explotación extrema del ser humano. In extenso en ESQUINAS VALVERDE: "El delito de trata de personas y sometimiento a esclavitud en el Código penal alemán" en El derecho ante las formas contemporáneas de esclavitud, cit., p. 399 y ss. El Código penal italiano tipifica tres delitos: el delito de sometimiento a esclavitud (art.600), el delito de trata de personas (art.601) y la compra venta o cesión de esclavos (art.602). El Código penal francés introdujo en 2013 junto a la trata de personas, el trabajo forzoso y el sometimiento a esclavitud (art.225). En Reino Unido, la Modern Slavery Act 2015, de 30 de marzo, tipifica de forma diferenciada el delito de sometimiento a esclavitud, de los delitos de trata. Puede verse una aproximación más detallada al derecho comparado en la materia en PÉREZ ALONSO: cit.,p 361. 
propios e independientes, según el grado de afectación del individuo sometido ${ }^{85}$, y de ese modo reprimir cualquiera de las prácticas prohibidas por el art. 4 del Convenio Europeo de Derechos Humanos $^{86}$. Ello podría implicar una remodelación de los tipos penales comprendidos bajo la rúbrica del Título $\mathrm{XV}$, para así diferenciar lo que es explotación pura y dura de lo que son condiciones laborales por debajo de las normas (el art. 311 previsto dentro de los delitos contra los derechos de los trabajadores no cubre todo el desvalor del comportamiento y resulta a todas luces insuficiente) ${ }^{87}$. Además, se debería contemplar en los delitos contra los derechos de los trabajadores la responsabilidad penal de las personas jurídicas. La previsión de la responsabilidad de las personas jurídicas en el actual delito de trata $\left(177\right.$ bis $\left.7^{\circ}\right)$, se extiende también a los delitos relativos a la prostitución, pero no incomprensiblemente a los delitos contra los derechos de los trabajadores. Resulta singular que por ejemplo pudiera responder penalmente la organización que capta a las personas objeto de trata pero no la responsable de los delitos de explotación cometidos a través de ella. De suerte, que consideramos necesaria esta previsión de cara a una futura reforma penal que implemente el nuevo Título "De la trata y la explotación de personas".

85 Resulta de interés la propuesta de BEDMAR, situando la esclavitud en el grado más alto de lesividad, al ejercerse un control absoluto sobre la persona, seguido de la servidumbre, como forma agravada de trabajo forzoso ("Concepción jurisprudencial de las formas contemporáneas de esclavitud" en El derecho ante las formas contemporáneas de esclavitud, Valencia, 2017, p. 243y ss.)

86 Con ese objetivo, también se ha propuesto la creación de un nuevo Título bajo la rúbrica "Delitos contra la libertad general y la personalidad jurídica" incluyendo junto al delito de trata los delitos de sometimiento a trabajo forzoso, servidumbre y esclavitud, en "Tratamiento jurídico-penal de las formas contemporáneas de esclavitud" PEREZ ALONSO en El Derecho ante las formas contemporáneas de esclavitud, ob. cit., p. 364

87 Otra opción alternativa sería introducir en los delitos contra los derechos de los trabajadores un tipo agravado relacionado con la víctima de trata laboral como propone POMARES El Derecho penal ante la explotación laboral y otras formas de violencia en el trabajo cit.p. 139. 
En suma, se trata de un fenómeno con muchas aristas que requiere respuestas globales, donde tienen protagonismo no solo el Derecho Penal sino también otros ámbitos del Derecho como el Derecho administrativo, el Derecho del Trabajo y en el que pueden llegar a intervenir muchas secciones del Ministerio Público, como Penal, Extranjería, Víctimas del Delito o Violencia sobre la Mujer, que se enfrentan a circunstancias muy excepcionales, como la clandestinidad de las víctimas. Sin embargo, una vez enmarcada la realidad aboguemos por continuar con la discusión social, política y académica con el propósito de contribuir a su prevención, erradicación y a la recuperación de la libertad, igualdad y dignidad de sus víctimas.

\section{Bibliografía}

ACALE SÁNCHEZ, M.: "Derecho penal y violencia de género: ¿un nuevo cambio de paradigma?" en MARTíN SÁNCHEZ (Dir): Estudio integral de la violencia de género, Valencia 2018 p. 439.

ACCEM: La trata de personas con fines de explotación laboral. Un estudio acerca de la realidad en España (Informe), 2006

ANDREU IBAÑES, R./ CARMONA ABRIL, M.: "La trata de sers humanos con fines de explotación sexual: una forma de violencia de género" en Dilemata, 2017.

BALES, K.: La nueva esclavitud en la economía global, Madrid, 2000.

BALES, TRODD, KENT: Modern Slavery. The secret world of 27 million People, 2009

BEDMAR CARRILLO, E.: "Concepción jurisprudencial de las formas contemporáneas de esclavitud" en PÉREZ ALONSO, E. (Dir.) :El derecho ante las formas contemporáneas de esclavitud (Valencia, 2017, p. 211 y ss.

CASADEI, T.: "Sujetos vulnerables, trata y formas contemporáneas de esclavitud: el papel de las instituciones" en 
PÉREZ ALONSO, E. (Dir.): El derecho ante las formas contemporáneas de esclavitud, Valencia, 2017.

CONSEJO GENERAL DEL PODER JUDICIAL: Guía de criterios de actuación judicial frente a la trata de seres humanos. 2018

CUERDA ARNAU, M.L.: "Torturas y otros delitos contra la integridad moral. Trata de seres humanos" en Derecho Penal. Parte.Especial, Valencia, 2015.

CUERDA ARNAU, M.L.: "Agresión y abuso sexual: violencia o intimidación vs consentimiento viciado" en VVAA: $L a$ Manada. Un antes y un después en la regulación de los delitos sexuales en España", Valencia, 2018,

ESPEJO MEJÍAS, P.: Hacia una reformulación de la violencia de género laboral, Madrid 2018

FARALDO CABANAS, P. "Donde están las víctimas de trata? Obstáculos a la identificación de las mujeres víctimas de trata en España", en Libro de Actas Conferencia Internacional "Día europeo contra el tráfico de seres humanos", octubre 2017.

FERNÁNDEZ BURGUEÑO: Análisis crítico de la jurisprudencia de la Corte Europea art. 4, 2017.

GARCÍA MERCADO, M.A.: "El problema de la esclavitud en Aristóteles", en Pensamiento 2008.

LAFONT NICUESA, L.: "Directrices básicas sobre la regulación de los delitos de trata de seres humanos en España" en PÉREZ ALONSO/ POMARES CINTAS (Coord): $L a$ trata de seres humanos en el contexto penal iberoamericano, 2019, p. 347

LAFONT NICUESA, L.:"El delito de trata de seres humanos en la jurisprudencia del Tribunal Supremo" en PÉREZ ALONSO, E. (Dir.): El derecho ante las formas contemporáneas de esclavitud, Valencia, 2017.

LLORIA GARCÍA, P.: "Una ley integral contra la trata, con perspectiva de género" en Agenda Pública, El País, 26 marzo 2019. 
MAQUEDA ABREU, M.L.: "Demasiados artificios en el discurso jurídico sobre la trata de seres humanos" en Liber Amicorum. Estudios Jurídicos en Homenaje al Prof. Terradillos, Valencia, 2018

MAQUEDA ABREU, M.: "Trata y esclavitud no son lo mismo, pero ¿qué son?" en Estudios Jurídico Penales y Criminológicos. En homenaje al Prof.Dr.H.C.Mult.Lorenzo Morillas Cueva, Madrid, 2018, p. 1251 y ss.

ORBEGOZO, I.: "La Víctima de Trata Sexual y su Desprotección en la Ley Integral contra la Violencia de Género 1/2004 (The Sexual Trafficking Victims and Desprotection in the Law Against Gender Violence 1/2004) en Oñati Socio-legal Series, v. 5, n. 2 (2015)

PÉREZ ALONSO, E.: "Tratamiento jurídico-penal de las formas contemporáneas de esclavitud” en: PÉREZ ALONSO, E. (Dir.): El Derecho ante las formas contemporáneas de esclavitud, Valencia 2017.

POMARES CINTA, E.: El Derecho penal ante la explotación laboral y otras formas de violencia en el trabajo, Valencia 2013.

POMARES CINTA, E: "El delito de trata de seres humanos con finalidad de explotación laboral" en RECPC, 2011

RAMÓN RIBAS, E.: "La intimidación en los delitos sexuales entre las agresiones y los abusos sexuales" en VVAA: $L a$ Manada. Un antes y un después en la regulación de los delitos sexuales en España", Valencia, 2018

RODRIGUEZ NÚÑEZ, "Los derechos humanos en la trata de personas" en Política criminal y derechos humanos, 2015 (en abierto)

RUEDA VALDIVIA, R.: "Hacia un nuevo sistema de protección de las víctimas de trata en derecho español" en $E l$ Derecho ante las formas contemporáneas de esclavitud, Valencia, 2017, p. 872 y ss.

SANZ MULAS, N.: Delitos culturalmente motivados, Valencia, 2018. 
SANZ MULAS, N.: Violencia de género y Pacto de Estado. La huída hacia delante de una norma agotada (LO 1/2004, Valencia, 2019.

SERRA CRISTOBAL, R.: "La trata de personas como una de las formas más atroces de violencia contra la mujer", en MARTÍN SÁNCHEZ (DIR): Estudio integral de la violencia de género: un análisis teórico-práctico desde el derecho y las ciencias sociales, Valencia, 2018, p. 271.

US DEPARTMENT OF STATE Informe sobre trata de personas 2018 (trafficking in persons report 2018).

VILLACAMPA ESTIARTE, C.: "Pacto de estado en materia de violencia de género: ¿más de lo mismo?” en Revista Electrónica de Ciencia Penal y Criminología. 2018, núm. 20-04, pp. 1-38. Disponible en internet: http://criminet.ugr.es/recpc/20/recpc20-04.pdf

VILLACAMPA ESTIARTE, C.: "El delito de trata de seres humanos en Derecho Penal español tras la reforma de 2015" en PÉREZ ALONSO, E. (Dir.): El derecho ante las formas contemporáneas de esclavitud, 2017.

VILLACAMPA ESTIARTE, C.: "La moderna esclavitud y su relevancia jurídico-penal" en $R D P C, 2013$.

VILLACAMPA ESTIARTE/ TORRES ROSELL: "Mujeres víctimas de trata en prisión en España", en Revista de Derecho Penal y Criminología, julio 2012 